\title{
Media-Political Process in Russia: Current State and Development Prospects
}

\author{
Natalya Rinatovna Balynskaya
}

Tatyana Pavlovna Rakhlis

Irina Vladimirovna Ritter

\author{
Oksana Sergeevna Pishchugina
}

Yuliya Leonidovna Kiva-Khamzina

Nosov Magnitogorsk State Technical University, Lenin Ave. 38, Magnitogorsk, Chelyabinsk Region, 455000, Russia Correspondence: Natalya Rinatovna Balynskaya, Nosov Magnitogorsk State Technical University Chelyabinsk Region, Magnitogorsk, Russia. E-mail: balynskaya@list.ru

Doi:10.5901/mjss.2015.v6n5s4p272

\section{Abstract}

The role of information is considerably increasing in the course of globalization process. The society simultaneously being the subject and the object of politics, exchanges information to coordinate its actions. Concurrence of actions is impossible without involvement into the political process. This article covers the interdependence of mass media and politics on the current stage of public relations development. The authors argue that a unified media political process has already been formed. However, this process cannot be put on the same footing as a political one only, since it uses a nonstandard resource for its development-information. Therefore, a media political process develops under a specific scenario, a nonlinear and often unpredictable one. Today, high quality information in the Russian mass media environment is a valuable resource. This increases the manipulative component of the mass media activity. Multiple tendencies influence on the development of the media political process in Russia: imposition of anti-Russian economic sanctions, wave reaction to them of both individuals, and small, medium, and large-scale businesses; the continuing search by Russian mass media for their own place in the political stage, which started in the 1990s; the influence of globalization in the field of information technology development; and the transformation of public conscience. Each tendency manifests itself in a contradictory and unpredictable manner, triggering reaction of all political actors in the information space. Actors here mean individuals, political parties, and states. The mass media process becomes virtually uncontrollable. The authors have consistently considered each of the stated tendencies and made conclusions on their formation and future development.

Keywords: information, policy, mass media, political actors, the media, the image of power, anti-Russian economic sanctions

\section{Introduction}

\subsection{Introduction to the Problem}

The Russian mediapolitical process is developing under a specific scenario. Multiple tendencies have certain influence: anti-Russian economic sanctions, the long-drawn process of self-identification of Russian mass media, the development of information technology, and the transformation of public conscience. All these tendencies have a contradictory impact on the society. The society since its appearance has always obeyed the laws of politics. All these factors turn the political process into a mediapolitical one.

\subsection{Problem Relevance}

The modern politics develops in the information space influenced by various factors, such as public requirements changing under the influence of global information processes; compliance/noncompliance of various mass media with the requirements of information consumers; changes in the structure of political actors; difficult access to unbiased information, etc. All these make the media political process in Russia nonlinear and unpredictable on the current stage of information relations development. Research has only recently approached this issue. Its deeper exploration requires a 
complex approach in several human sciences both in Russia and in other countries. The reason of that is the involvement of Russia and other countries in the global information processes. This inevitably affects all aspects of the information exchange.

\subsection{Problem Study}

Many researchers argue about the interrelation of politics and mass media. Thus, George Comstock and Erica Scharrer in their article "The New Media" concerned the changes in relations between mass media and politics and the transformation of those actors who influence on mass media: "Three factors are largely responsible for the ascendant role now assigned to the media. The first factor is the critical reexamination of the paradigm employed by these early investigators that assured a highly circumscribed role for the media. The second factor is the diminution of parties as the chief factor in determining the choice of most voters. The significance of television is not that it dominates media use, but that it reached the portion of the public eager for news and vulnerable to political advertising at a time when the barriers to influence abbreviated by the term personal history were in retreat. The ties with the government went far beyond the ties between parties and newspapers and the partisan outlook of many papers. They included a wide range of financial support, although some of it was disguised, and a set of conditions favorable to the prospering of the press. The press in the United States has always closely followed and even attempted to shape politics. What began as overt partisanship in the treatment by newspapers of political candidates shifted with the ability to mass produce and mass distribute newspapers (Comstock \& Scharrer, 2010).

The Russian science of mass media focuses on relations between authorities and mass media. The researchers note, "mass media are an information field where the image of power is created". Of course, this system has a certain sequence of interaction set by the parties of information relations. The main actor and "orderer" of image modules promoted in the public conscience is the power (Balynskaya \& Kovaleva, 2015).

The researcher Bolshakov claims, "The increasing interest in online media is being observed. Today, it is more favorable to read news on the Internet rather than to buy a newspaper. The population that was accustomed to printed media will disappear soon and shift to the Internet. On the crest of the crisis, many printed publishing houses closed their printed versions. However, they actively and successfully develop on the web, which is an important fact. The next outlined tendency is paid subscription for digital media, i.e. access to verified and valid information becomes fee-based (Bolshakov \& Bolshakova, 2014).

The limited access to unbiased information raises the issue of elections legitimacy. This occurs because the platform for civil society is the understanding of political situation through the information provided by mass media. Further, this information undergoes the following stages: ranking, comparison with a certain reference, identification of the difference, the feeling of motivation to change the current situation, and, as the result, a political action. In the circumstances of the intensively changing election legislation and absence of proper comments from wielders of power, it results in an increased level of non-confidence among population. The aggregate consequence of these processes is the unpredictable activity of electorate with regard to the transformation of the political process.

In the modern world, communication is also being transformed, which "initially was represented as a linear process of message transfer and is now extending beyond own limits. "Transformation" as an "in between" state paradoxically establishes the succession of the derived elements and their properties with regard to the initial ones. Being "embedded" into the network organization of space and reflecting its "world", the modern communication is exposed to changes more than ever. On the one part, an open and decentralized network enhances the communication's capabilities, and on the other hand, it makes communication unstable with a risk of permanent failure" (Ivanova, 2014).

All this motivates researchers to consider the mediapolitical process as a nonlinear process preconditioned by the specific behavior of the information exchange actors.

\subsection{Hypotheses}

According to the authors, two main widely spread hypotheses about mass media can be developed using the generalization method. These hypotheses will help to get the final image of mass media and politics cooperation in Russia on the current stage of public relations development. The first hypothesis is represented by researchers who claim that the manipulative component in politics is related to the fact that mass media are manipulatively influenced by many actors like authorities and business (Lozovskiy, 2010).

Another hypothesis is exactly opposite. In accordance with this hypothesis, mass media have a manipulative impact on all political actors, since many mass information activities are carried out through mass media: journalism, 
advertisement, and public relations (PR).

The authors find the second hypothesis the most relevant. This can be explained by the functional approach to mass media's activities in politics, which attributes a special function to mass media in politics. In accordance with its functional nature, in the first instance, mass media are the means of information transfer from the subject (the government authorities) to the object (the society), which is exposed to the political action. However, political life in Russia had a period, when mass media became a rightful participant of the political process due to the uncertainty in the political power. At that time, mass media became an independent actor in politics and had a sufficient influence on the formation of political preferences of citizens. This allows us to claim that mass media in Russia are a rightful political actor strongly influencing on the trends of the media political process.

\section{Methodology}

\subsection{The Causes of Media Policy Specificity}

We used the conventional document analysis method for studying the media political process. This method allows us to evaluate the content of certain mass media covering current political topics. According to our survey, the topic of antiRussian economic sanctions is the most debatable one. This is important for understanding of the contradictions occurring due to the actual state of affairs in the Russian economy and the image that is impregnated into the collective consciousness of Russian citizens.

The authors also use sociological tools required for obtaining information on the public opinion concerning the most important issues. Both sociological surveys and a content analysis of relevant newspaper articles are important for us.

The authors used the comparative analysis method to identify the similarities and differences between expert opinions represented in digital and print media. The following should be noted: printed media cover larger audience, since they, unlike digital media, are strictly oriented in terms of the audience's preferences.

The authors also exploit the opportunities of the historic method. Evaluating the features of the media political process development and forecasting its further development trend is possible only by actual estimation of historical realias.

There are multiple causes for occurrence of a scenario, according to which the media political process develops in Russia, as well as the causes for its specific manifestation. Here are the main ones: introduction of anti-Russian economic sanctions, wave reaction of population concerning the sanctions; continuing searching for the place on the stage of politics by Russian mass media; influence of globalization on a single aspect; development of information technologies; transformation of public conscience. Let us consider each of reasons in detail.

\subsection{Anti-Russian Economic Sanctions}

Anti-Russian economic sanctions resulted from reasonable actions of the Russian authorities to establish a multipolar world. This instigated a counter reaction of the West in a form of anti-Russian economic sanctions. It became evident almost right away: anti-Russian sanctions will have a negative effect on the condition of the Russian economy because of the strong dependence of Russian manufacturers and service providers on import deliveries. Let us consider the statistical data: according to expert evaluation, Russia's dependence on foreign software is $90 \%$. "Currently, the Vbydecreased due to enhancement of the Russian companies' presence on the global market of IT services," reported Nikolai Nikiforov, the Head of the Ministry of Communications of the Russian Federation. "The Russian presence on the global software market does not exceed 2\%," added the minister in his video address to the participants of the "Import Substitution in the Area of Software in Russia" Forum.

There are several sectors in Russia that are the least dependent on import deliveries. Igor Nikolayev, the Director of Institute of Strategic Analysis for Financial and Accounting Consultants, told about these sectors. He emphasized that Russia depended on western deliveries almost in all sectors, including the processing and mining industry. There is a strong dependence in aviation and car industry that were developed mainly with a help of foreign manufactures, which built plants in Russia. Agriculture and food industry are less dependent.

However, even agriculture and food industry are not ready for 100\% import substitution. This is due to the mindset of Russian entrepreneurs. It should be noted that there were no production sectors in Russia, in which entrepreneur started their businesses from scratch. Let us clarify the authors' position. Entrepreneurship in Russia was initially oriented to the west and this can be explained. One the one hand, the collapsed planned economy of the USSR, the transfer to the market mechanisms revealed new perspectives for the Russian entrepreneurship. However, on the other hand, these 
events in the Russian politics and economy demonstrated the backwardness of the Russian production sector and science in comparison to the global ones. In the late $20^{\text {th }}$ century, under the conditions of that period, it was almost impossible to commission own high quality manufacture, as it was easier to copy western technologies, improve them, or adapt to the Russian environment. Russian enterprises chose the path of least resistance. This problem definition explains why there was no necessity to invent something new. Therefore, production in many sectors was based primarily on western technologies. The manufacturers operated smoothly for a long period without economic crises. This created an image of stability in the country.

This problem definition explains why anti-Russian sanctions did not cause panic among Russian population initially. On the contrary, the rise of public opinion was induced by the governmental appeal to shift for import substitution. However, the euphoria did not last long. This is connected with the fact that a year after almost every Russian citizen felt the consequences of crisis. Reduction of purchasing power is a natural response for economic crisis. Then the substitution of expensive products with cheaper ones occurs (if possible). An increase in the level of unemployment also has an impact. Based on social surveys data, the current official unemployment rate in the Ural region is $6 \%$. A part of entrepreneurs who managed to maneuver under the current economic circumstances and provide cheaper products for consumers, earned much during the crisis. However, this part of entrepreneurs is inconsiderable. A major part of entrepreneurs stumbled upon significant issues.

The Chelyabinsk Tractor Plant LLC, the largest one in Russia, works primarily using the Siemens equipment. AntiRussian economic sanctions had negative effect on the plant status, which had to reduce its staff by $17 \%$. According to analytical forecasts, this is not yet the final value, as Siemens continues to reduce the scope of deliveries to Russia.

Not only the large business, but also medium-scale business faces the same problems. Printed goods production is the object of analysis in this case. This example allows for a detailed analysis of the considered problem. Almost all printing works used foreign paper and printing ink for manufacturing. After introduction of anti-Russian economic sanctions, it is not possible to find a complete analog of Finish printing ink in the Russian Federation. This can be explained by the fact that manufacture of local inks was not necessary for a long time. Today, foreign resale schemes are implemented to import ink through eastern countries to Russia. It makes manufacture of printed goods more expensive. This causes the reduction in the number of orders, consequently resulting in production cutback and staff reduction. Rubtsov A. provided his estimate of these tendencies. He considers the aggravation of situation as not just deindustrialization, but as idle modernization: "We have already backslidden into pre-manufacturing epoch... The scheme is the same: at first, it is easier to buy from someone, and afterwards there is nothing to restore using own means. Creative people are not required as a social class for this kind of life. Passive population living in municipal communities in the number of people sufficient for mining and transportation of raw materials, serving for the good living based on the natural resource rent... your modern age is fully dependent and based on import" (Rubtsov, 2015).

It should be noted that this scenario of economic events development supported neoliberal institutionalism established in the early 1990s. It forced the state out of the economy and the notion of "industrial policy" became a taboo. This meant actual degradation of the major part of manufacturing sectors. For twenty years, economists and experts once and again highlighted the dangerous and rapidly increasing import dependence of the country. Mass closure, bankruptcy, and privatization of formerly successful enterprises, as well as a loss of professional staff accompanied all this.

\subsection{Mass Media Influence on the Public Opinion}

Obvious contradictions are quite visible on the modern stage of public opinion formation in Russia. On the one hand, it is evident that almost all Russian citizens experienced consequences of anti-Russian sanctions. On the other hand, the results of public opinion study evidence that Russian citizens support the chosen course. The unprecedented rating of the Russian president speaks for it. "Since the rating's boom in March after joining Crimea, Vladimir Putin's rating has remained at the $85 \%$ level in December. The "Crimean consensus" put Mr. Putin in the center of the political system: citizens do not believe in the possibility of any alternative, and all institutions of the state depend upon his success. Television has become an important link of consolidation: federal TV channels achieved new records of audience number in 2014 (Ivanov, Korchenkova, \& Goryashko, 2015).

Television becomes the major means for building the general trend of public opinion formation. This tendency can be traced in the Russian mass media reality for a considerable period, and it appears that it will exist in future. It is possible to highlight several points of the scenario used to form an image of power in public opinion through audiovisual mass media.

In the first instance, it is necessary to create an image of governmental authorities as a "center" having all relevant information related to a certain issue. Then, this image is integrated in minds stage by stage focusing on positive and 
favorable moments. This is done through a response to certain negative events in the Russian economy. In addition, the thought about possible positive progression of events is integrated, as well. It relates to the situation in general and to certain manifestation of negative consequences of anti-Russian sanctions. Then the positive image of power is fixed in mass consciousness. This becomes possible due to the frequently mentioned positive image, as well as through arrangement of media discussions supporting the authorities' actions.

\subsection{Globalization Influence on the Mass Media Process}

Global tendencies also have impact on the formation of the mass media process. For instance, governmental and local authorities of western countries long ago implemented the electronic workflow both within institutions and in communication with population. However, in Russia, these processes only start being implemented en masse. In many respects, this is related to the level of information technology development. In this regard, researchers say, "the use of information technology provides new opportunities for an increase in the effectiveness of public administration and local government, and ensures more optimal use of resources, performance of duties, and increase in the transparency of managers' activities, saving their time (Kanaeva, 2015).

In Russia, these trends have not yet become widespread and one of the directions of the media political process is associated with that. Consumers of public and municipal services are divided into two categories. The first category of citizens is those who quickly adapted to innovations. This part of information consumers has learned how to use electronic resources effectively to submit petitions to the government. This includes various actions starting from electronic payments and ending with appeals to the digital reception of President of the Russian Federation. The second category includes those who have no access to electronic resources. The resources may be unavailable due to psychological characteristics. The older generation has no skills for electronic communications and is not able to transfer money electronically, use the portals providing public services, and control their personal accounts for payment of taxes and charges. In addition, electronic resources may be unaffordable to the middle class. The Internet is unaffordable for people with a low level of income. If we take into account the economic aspect, we can say with confidence-the economic crisis has significantly affected the increasing difference between the part of the population that uses the opportunities of the Internet, and those for whom it is unavailable.

Let us pay attention to another problem. It manifests itself in the relation to those who have access to technology and are permanent consumers of information through electronic resources. It is important for this category of people to get objective information. However, today, as the authors believe, the main problem in Russian politics is the access to unbiased information. This relates to both individual political actors and groups. The problem is not only in the fee for the information. The following question arises: what information can be considered unbiased? The problem is in fact that at the current stage of public relations development, the source of information and its distributor coincide within the frames of a single actor.

Such a situation in information generation has not yet been observed throughout the history of humankind. There are several reasons for this situation. In the first instance, there has always been an alternative source of information, who had the opportunity to deliver his position. The entire opposition system of mass media in any country is based on this. However, in modern conditions, there is a "generator of information" that determines what can be considered a fact is and what cannot. As an example, "Wikipedia", a widespread online encyclopedia, is financed by "voluntary contributions of members". The most generous contributor of it is the American public multinational corporation Google: "The founder of the Wikipedia online encyclopedia Jimmy Wales said on his Twitter microblog that Google made a donation to Wikipedia's fund amounting to USD 2,000,000".

This proves the enormous manipulative role of the mass media in the modern society. Globalization trends are obvious. Under these circumstances, the following question becomes relevant: Can Russian media carry out the process of self-identification in the changed historical and legal reality?

\subsection{The Process of Self-Identification of Russian Mass Media}

Russian mass media continue to search for their own identity. This process was started during the period of transition to the market economy. Then, due to the uncertainty in the field of power, mass media were able to influence on the public opinion formation largely.

According to the theory of the Soviet press, mass media in the Soviet Union were conceived as an agitator, propagandist, and organizer in relation to information consumers. However, another trend that existed at that time should be mentioned as well. 
Upon their occurrence, Russian mass media existed within the framework of Russian literature for a long time. Literature has always been perceived by the Russian public consciousness as a teacher of life, a mentor. We believe that the Russian journalism also fulfills this function.

Thus, genetic memory encourages the audience-consumers of information-to demonstrate their goodwill to mass media. However, there is a problem of capital management. The current political reality shows that each specific mass medium is backed by a particular financial interest. This capital significantly affects the coverage of political events and formation of attitudes. Is there a civilized way out of this contradiction? The authors are convinced that the solution was found by Western mass media that openly and publicly provide information about their founders as well as the major shareholders of publishing houses and media holding companies.

This position, in our view, helps preserve readership. Moreover, it allows to increasing the audience because the undefined segment of readers has all the information to make an informed choice. We see further development of the information exchange in Russia under a similar scenario. Only an open dialogue with the audience based on "equal terms" is able to attract supporters of a mass medium and increase its circulation. Such a dialogue can significantly influence the development of the political process due to constructive discussion on the part of all participants-the actors of political interactions.

\section{Conclusion}

We have shown that multiple tendencies influence on the development of the current media political process in Russia. These tendencies include imposition of anti-Russian economic sanctions and the wave reaction of the population to the sanctions; the continuing search for an own place on the political stage by Russian mass media; influence of globalization on separate aspects; development of the information technology; and transformation of public conscience. Now, it is important to determine the trends for further development of the media political process. To our opinion, there are several trends. Sometimes, such trends are contradictory. On the one hand, this is the inevitably developing democratization. On the other hand, the strengthening of the manipulative component that is similar to political PR and advertisement. Further transfer of politics to virtual environment will also continue.

\subsection{The Increasing Democratization of Media Policy}

The information aspect of the policy has equalized all political actors. They are equal in terms of generation and distribution of information. Any participant of political interactions can create a news hook. The most common method is replication of a comment about any significant political event. Experience has proven that such a comment generates new comments, directing the discussion in an unpredictable direction. At one time or another, the entire set of comments may become the public opinion, if it is expressed clearly and structurally. In addition, this is the basis for the authorities to respond to the situation. The response is represented in the form of ready-made solutions that are able to influence on the future course of the political process.

According to this scheme, the environment is able to influence on the political system. This makes all the political participants interdependent. If the authorities receive an impulse from the external environment and interpret it incorrectly, they will take an inadequate political solution at the output. This will enforce the environment for action. These actions may come out in the form of discontent with the implemented policy and in the form of distrust in the government.

This diagram shows how political actors depend on each other. The authorities need adequate information about the expectations of the population. This is important not only for the elaboration of effective solutions on the part of authorities. Authorities always strive to maintain themselves as a group. This prompts them to monitor carefully various impulses emanating from the environment. The population expects solutions from the authorities that can make their life easier during the economic crisis.

The understanding of several presuppositions will facilitate the development of democratic tendencies in media policy: the understanding of the interdependence, as well as of the fact that today policy develops in the information field. All actors act on equal terms in the mass media field.

\subsection{Reinforcement of the Manipulation Component of the Media Political Process}

The opposite trend will manifest itself at the same time: the strengthening of manipulation by some political actors. This is due to the specificity of information as a resource. Nowadays, politics moved into the sphere of information. It makes us think about the information as a resource of power. The information cannot be put on a par with other resources that are 
traditional for politics.

For instance, let us compare information with the force resource. The more the government uses the force resource, the more this resource is depleted. This statement does not apply to the information resource. On the contrary, it is enriched with the increasing knowledge about the response to its use. Using the force resource requires physical, time, moral, and ethical efforts. The information resource is able to reach maximum audience for an extremely short period. This occurs without any physical or other efforts. All this highlights the information resource among others and makes it special.

There is another peculiar feature. The information resource can be held by a single actor-the generator of information. This fact considerably increases the manipulation capability in the field of politics, economics, etc. It seems that we will observe maximum concentration of the manipulative aspect in events coverage in the nearest future. This phenomenon will be close to political PR and advertising by its functional orientation. Let us recall that political advertising, as well as PR, refers to the types of mass information activities that are known to form their actions on a biased basis. In this respect, journalism is not able to initiate news hooks, as it always comes after the fact. Advertising and PR have virtually no limiting factors in this regard. Advertising creates a political product-the image of a certain politician, party, or country. Political PR using the information about the public sentiments is able to integrate solidly the image in the public consciousness. Today, we can see a tendency that ordinary consumers of information cannot distinguish high quality unbiased information from artificially created one. Therefore, the authors believe that manipulative techniques will be developing.

\subsection{Further Transfer of Politics to the Virtual Environment}

The role of information in the world increases. Modern politics demonstrates that it is not necessary to use the force resource to influence on the development of the political process. It is enough to apply the information resource only. This proves that the further development of politics will be transferred to the field of information and information technology. It will make the world even more interdependent.

Despite the fact that the political process becomes more impetuous, multi- aspect, and multi-subject, the actual politics becomes less intense. Let us explain that. To express the attitude to current events, one must not participate in political actions. He can do without rallies, protests, and demonstrations. It is enough to set a virtual information process in a certain direction by posting a comment, voting online, or sending an electronic claim. This makes a single person as an actor of politics, and a group actor of politics (e.g., a political party) distanced and separated by virtual space of events.

All the declared tendencies have not yet been sufficiently reflected by either Russian, or global science. A comprehensive approach is required for their interpretation. The authors are convinced that such an aggregate approach to solving problems will become apparent in the nearest future.

\section{References}

Balynskaya, N. R., \& Kovaleva, M. M. (2015). Specifics of creating the image of power in the media (by the example of Chelyabinsk Oblast). Voprosy Upravleniya, 6(12), 31-53.

Bolshakov, S. N., \& Bolshakova, Y. M. (2014). Trends of the Russian Internet segmet development. Ekonomika i Politika, 4(6), 7-11.

Comstock, G., \& Scharrer, E. (2010). The psychology of media and politics.

Google sponsoring Wikipedia. Retrieved from http://www.linux.org.ru/forum/talks/5360821

Ivanova, O. E. (2014). Transformation of communication as "anything goes." Sotsium i Vlast, 2(46), 7-11.

Ivanov, M., Korchenkova, N., \& Goryashko, S. (2015). One in a Majority. Kommersant, 05.

Kanaeva, E. I. (2015). The role of information technology in management process. Ekonomika i Politika, 1(4), 51-52.

Lozovsky, B. N. (2010). Manipulative technologies of influence on mass media (Extended abstract of Doctor's thesis). Yekaterinburg.

Rubtsov, A. The order in chaos: How to get out of the political postmodern. Retrieved from http://www.forbes.ru/mneniya-column/t sennosti/256911-blizhe-k-zemle-chem-obuslovlen-povorot-k-konservativnym-tsennostyam

Who finances Wikipedia? Retrieved from http://www.bolshoyvopros.ru/questions/471314-kto-finansiruet-vikipediju.html 